\title{
Organizational solutions to improve timeliness and effectiveness of the stroke care
}

Maria Crema ${ }^{1}$, Chiara Verbano ${ }^{1 *}$, Jacopo Guercini ${ }^{2}$, Caterina Bianciardi ${ }^{2}$ and Vincenzo Mezzatesta ${ }^{2}$

\begin{abstract}
Background: Saving time means saving neurons in stroke care process. Managerial and organizational solutions that lean the processes should be considered in order to overcome the effects of stroke, which is the second worldwide cause of death. The purpose of the paper is to understand how Health Lean Management (HLM) can be adopted to achieve a more efficient stroke care process. In this peculiar context, efficiency enhancement leads to safety and effectiveness results. For this reason, the investigated projects have been recognized as Lean \& Safety (L\&S) projects, being HLM projects reporting patient safety improvements.
\end{abstract}

Methods: Due to the peculiarity of the project to investigate, a holistic case study has been conducted in a university hospital of Tuscany region. Thanks to the research framework developed in the literature for L\&S projects, data regarding motivations, objectives, organizational and managerial aspects, outcomes, enablers and obstacles of the project have been collected and analysed.

Results: A multidisciplinary team, already trained on HLM and supported by the top management, was created and the step-by-step Six Sigma approach was adopted. After a mapping phase, a value stream map was created, Key Performance Indicators were defined and, finally, the Door To Needle (DTN) times and the modified Rankin Scales (mRS) were measured. Thanks to root cause analysis, the identified wastes were analyzed and intervention actions were defined and implemented. They regarded mainly different organizational interventions and they led to a decrease of both DTN times and mRS.

Conclusions: The analysed project has demonstrated how it is possible to obtain relevant operational and clinical outcomes through organizational solutions. The analysis of this project, in which pursuing efficiency has led to safety and effectiveness results, has demonstrated how these different performances are linked each other in some peculiar care processes, in which shorter time means more effective and safer care, as in the stroke case. The implementation of L\&S projects can improve care processes, providing a contribution to realize a more efficient, effective and safer healthcare system.

Keywords: Health lean management, Stroke care process, Healthcare effectiveness, Healthcare efficiency, Organization

\footnotetext{
* Correspondence: chiara.verbano@unipd.it

${ }^{1}$ Department of Management and Engineering, University of Padova,

Stradella San Nicola, 3, 36100 Vicenza, Italy

Full list of author information is available at the end of the article
} 


\section{Background}

\section{Criticalities of the stroke care}

Each year, about 17 million people experience a stroke worldwide and more than 6 million die [1-3]. Stroke is considered the second cause of death (about $11 \%$ of total deaths) behind heart disease, even if for the developed countries a decrease of the mortality rate has been reported for all the types of stroke $[1,3]$. Stroke can regard blood clots, which cause dysfunctions of the brain (ischemic stroke), or blood vessel in the brain due to bleeds (haemorrhage stroke) [2]. The incidence and mortality rates vary considerably among countries and it is probably due to different risk factors (e.g., lifestyle, environmental factors, genetic factors), but also to diverse stroke management practices [4]. In Sacco et al. [5], the prevention of stroke through the detection of silent vascular lesions is highlighted, in addition to the need of a "prompt and timely diagnostic evaluation and treatment". The effects of the stroke can be different depending on the part of the brain that has been damaged and on its severity (how much it has been damaged). The time factor is extremely crucial in the case of a stroke. As stressed by Gomez [6] "time is brain". In the literature, it is clear that shorter Onset to Treatment Time (OTT) (time from the symptom onset to the treatment) and Doorto-Needle Time (DNT) (time from the arrival in emergency department to the treatment) provoke improved clinical outcomes and fewer complications [7]. Each wasted minute is determinant in the stroke care; for instance, lack of treatment of a supratentorial ischemic stroke implies the loss of 1.9 million neurons per minute, which means almost 3.6 years of aging, as estimated by Saver [8].

According to the guidelines developed by the American Heart Association [9], the OTT should not exceed $90 \mathrm{~min}$, spending at maximum $60 \mathrm{~min}$ for DNT (in the hospital). Although the majority of US and European hospitals are not able to meet the requested time limit for DNT, Smith and von Kummer [10] believe this threshold should become a rule, not an exception. In order to comply with this time constraint, managerial approaches can be helpful. Li and Johnson [7] mentioned studies of process improvement where the OTT has been significantly reduced. Educational campaign to recognize the stroke symptom and the use of mobile tools have decreased the pre-hospital times [9, 11]. Also for DNT positive results has been achieved in [12-15]. In particular, in [13] time reduction has been achieved by conducting a value stream analysis with the aim at streamlining the intravenous tPA protocol. However, in this study a significant improvement in terms of clinical outcomes was not reported, since OTT (reduced from 131 to $111 \mathrm{~min}$ ) was still over the limit of $90 \mathrm{~min}$ requested in order to obtain significant increases of the modified Rankin Scale through the adopted changes.

\section{Lean Management to improve stroke care}

Among the different managerial approaches that can lead to process efficiency raise, in the last decades interesting results have been obtained thanks to the adoption of Health Lean Management (HLM). That managerial methodology was adopted at the beginning only in manufacturing sector. Nowadays, it is diffusing in services and in particular in healthcare, where it has been adopted as a principle to streamline processes, reduce costs, care more patients without adding resources [16]. According to [17], five principles should be followed, starting from defining accurately what is the value from the patient point of view. The activities that add value to the process should be distinguished from the not added value activities. Then, the entire value stream should be recognized, mapping the processes and identifying all the wastes. Adopting the HLM tools and practices, the process can be streamlined, eliminating wastes and complying with the third principle of the lean management: make the product (or service) flow. According to the forth principle, it is suggested to follow a pull approach, which means starting all the process upstream activities only after a request by the customer is received. The last principle consists in continuing to improve the process aiming at perfection. The precondition for the adoption of HLM, complying with the over mentioned principles, is the development of an organization that is based on the process concept, according to system logics, and on the reduction of wastes and process continuous improvement [18].

As stressed by Li ad Johnson [7], rather than requiring that everything goes faster, the entire value stream should be analysed, in order to eliminate the activities that not add value.

However, searching on academic databases (such as Scopus of Web of Science), combining the words "stroke" with "lean management" (with the boolean operator AND), few papers regard the adoption of HLM for caring stroke (e.g., [7, 13, 19-21]). Moreover, in these papers the implementation process of the HLM project is not sufficiently detailed. Therefore, the potentialities and the results of adopting HLM for the stroke care are all to be explored. In the literature, studies on L\&S projects, defined as HLM reporting patient safety improvements [22], have demonstrated the possibility to achieve positive results in terms of patient care, besides process efficiency [23]. The positive clinical results in the case of stroke are obtained as consequence of process efficiency outcomes. For this reason, an improvement project can start pursuing efficiency objectives, which will lead to effectiveness results, in addition to a reduction of the risk of not being promptly treated. 


\section{The context of the analysed project}

The project selected and analysed in the following was suggested by the stroke unit manager of the "Azienda Ospedaliera Universitaria Senese" (AOUS, the University Hospital of Siena, "Santa Maria Le Scotte", Italy), after his participation at the 2013 "Lean Day", a yearly competition performed inside the AOUS. The latter is a centre of national importance and high specialization. Currently, it employs around 3,000 people between hospital and university and it is equipped with about 650 inpatient beds and 75 beds for day hospital/day surgery. In 2015 , it provided about 3,000,000 health services, 40,000 hospitalizations, over 8,000 of which related to foreigners and patients who don't reside in its region (Tuscany). From an organizational point of view, the AOUS is divided into seven departments characterized by integrated activities (medical care, teaching and research).

The units which took part in the project were: the stroke unit, the neuroimaging and neurointerventional unit, the emergency department, the radiology unit, the chemical analytical laboratory and the emergency service. The project was developed mainly with the contribution of the physicians in the stroke unit, which is part of the Neurological and Neurosensory Sciences Department and was inaugurated in 2008; patients with cerebral vascular pathologies are hospitalized in this area. The clinical pathway in the stroke area is organized depending on care intensity: there is a para-intensive and an ordinary inpatient hospitalization. There are 8 beds, all monitored, in which nursing care is provided $24 / 24$ h. Patients clinically stable are transferred in ordinary inpatient ward, where there are other 10 beds. The Stroke Unit of Siena is a referral centre for the south Tuscany area, and from 2008 has increased considerably the number of patients treated with systemic thrombolysis.

In 2012, the AOUS decided to include lean thinking as a part of its strategy, in order to promote continuous improvement at every level. Translating this strategy into action, in 2013 a Lean Office was established; its aim is to improve the processes and to grow "lean thinkers" whose know-how is increased by the daily practice of continuous improvement. Nowadays, the AOUS is considered as one of the first mover organizations in Italy with appreciable HLM results [24].

\section{Research purpose}

Italy is not the country with the highest number of deaths for stroke, but in the analysed case there was a strong willingness to reduce the DNT. The purpose of the paper is to extend the knowledge about how HLM can be adopted to achieve a more efficient stroke care process, investigating its results in terms of operational and clinical outcomes. Operational results are primarily pursued and they regard for example the achievement of shorter admission times or other efficiency increases thanks to the adoption of HLM tools. On the other hand, clinical results derive from the operational ones, and are linked with the effectiveness of the care from a medical point of view. The final intent of this paper is to spread this positive experience, to learn and promote further improvement projects in other hospital settings, obtaining a safer stroke care for the benefit of the whole society.

\section{Methods}

In order to pursue the research objectives, the managerial (referred to phases and the adopted tools) and organizational aspects of HLM projects in stroke process care should be investigated. Moreover, the operational and clinical outcomes have both to be analysed. As emerged reviewing the literature, the adoption of HLM for stroke process care improvement is not so diffused and the selected case is one of the few projects implemented to this extent. Therefore, the selection of a holistic single case study is justified by the purpose of the paper, but also by the novelty of the investigated topic, since case study is preferred for exploratory research and theory development $[25,26]$. A holistic case study allows to study in depth different features of a specific setting in an organization. In the project selected for the investigation, pursing efficiency increase, positive results in terms of patient safety and care effectiveness should be reported for the over-mentioned specific characteristics of the investigated care process. It constitutes a peculiar type of L\&S projects, wherein efficiency and effectiveness are usually pursued in an integrated way, analysing the processes to identify and solve operational wastes and clinical errors. For that reason, in this paper the research framework created by [22] has been adopted. Thus, for data collection and analysis, the following elements have been considered:

- Motivations and objectives;

- Organizational aspects: key roles, top management and external support, training, role of clinical risk management, employee involvement, team, meetings;

- Phases, tools and practices;

- Outcomes: operational results, change of organizational system, employee satisfaction;

- Tools and practices to sustain the implemented interventions and the HLM adoption;

- Enablers and obstacles.

For data collection, multiple sources were considered, such as interviews with structured and open-ended questions, involving the people of the Lean office. In 
particular, the data provided by the interviewees regarded firstly the general information about the hospital, in terms of size, organizational structure, HLM experience. Moreover, the questions of the protocol concerned the motivation that triggered the project, the defined objectives, the support obtained by the hospital top management, the composition and the organization of project team and its key roles, the staff involvement and training and any involvement of the of the clinical risk management staff. Furthermore, the interviewees provided details about the phases and the tools adopted during the project realization, regarding the planning, the implementation, the monitoring and the evaluation of the project. In particular, for the project outcomes, besides investigating any operational results, the researchers asked if there had been changes of the climate and the organizational system (new employees, changes of the roles, the functions, the procedures) deriving from the project. At the end, in addition to the identification of the enablers and the obstacles of the project realization, the aspects that facilitated the sustainability and the continuity of the project have been investigated with the interviewees. Archival documentation regarding "Lean Day" and a report of the project were also analysed to triangulate data. The results of the framework adoption have been shared and verified by all the authors. Following the example of [27], in order to avoid bias and increase the objectivity, as two of the paper authors were part of the project team (participants in the study), data access and collection were performed mostly by the members of the Lean Office, while the other authors conducted the data analysis and discussion. In particular, data were coded and classified according to their relevance with the over mentioned elements of the research framework. Moreover, statistical analyses were conducted in order to investigate the operational and clinical results obtained thanks to the project implementation. In particular, using the software SPSS statistics 17.0, the non parametric Mann-Whitney test was performed to compare the DTN times and the modified Rankin Scales, obtained before and after the project implementation. Other statistical analyses were executed by the project team in order to analyse the project results, calculating the stroke process times and correlating the DTN time with the different days of the week and with the patient age and sex. The analysis and the discussion of all the results were carried out continuously asking clarifications and checking the gathered case data with the members of the Lean Office, as suggested by [25].

According to [27], the adoption of an existent conceptual framework for the analysed case permitted also to refine the developing theory for L\&S projects, comparing the recognized features of the project with those published in the literature as requested by the analytic generalization [25].

\section{Results}

The project selected aims at reducing DTN time in acute ischemic stroke, identifying barriers, inefficiencies and solutions to improve the delivery of acute stroke care. This project was part of an international observational study carried out by the "Safe Implementation of Treatments in Stroke International Network" (http://www.sitsinternational.org/) that was labelled "SITS WATCH". According to that study, the project objective was to achieve a DNT of $40 \mathrm{~min}$ for at least half of the ischemic stroke patients treated with systemic treatment (intravenous infusion of plasminogen activator in patients with the stroke syndrome). In order to achieve this aim, the involved hospitals implemented logistic, organizational or technological interventions; the AOUS decided to follow the HLM approach.

\section{Organizational aspects of the project}

The team was built asking each unit manager to appoint a referring physician and another person active in the field of application (a nurse, a technician, or a healthcare and social assistance operator). In this way, five referents were chosen: emergency medical services director, emergency department director, radiology technician, radiologist, clinical laboratory director. The team was multidisciplinary, involving people from diverse parts of the patient flow (emergency department, radiology, stroke unit, clinical laboratory, lean office), for a total of 22 persons. The leader of the project was a stroke unit physician, while the tutors and the project managers were two members of the Lean Office. A strong support came also from the top management that not only undertook the planning process, but also facilitated the implementation process; kick-off and further meetings were performed involving the medical director. Most of the team members (15 of the 22 people) had attended at least one of the courses about HLM provided by the Lean Office. Training to the team was provided also on the job, during the meetings that took place at the beginning of the project, in order to present the schedule, the tools and the goals. The latter were firstly defined with the team sponsors (stroke unit director and inpatient unit manager) and finally decided with all the team members, during the first meeting. To map the actual situation (current state Value Stream Map) and list the problems and the inefficiencies other two meetings with the whole team were necessary. After that, the team defined the countermeasures to test the project feasibility in a pilot experiment. The whole team met again also to define a new value process; other meetings still take place to monitor periodically the performances of the project. 


\section{Managerial aspects of the project}

After a planning phase performed with the stroke unit director for the realization of the project, the team followed the step-by-step approach of the Six Sigma program, considering the DMAIC (Define, Measure, Analyse, Improve, Control) methodology [28]. In the define phase, first of all the project charter was developed, then the value stream map was drawn and the Key Performance Indicators (KPIs) were defined. Starting from the current situation, the process from "door to needle" was divided into different steps. For each step the team defined patient and information flow, but also process and waiting time from a step to another (Fig. 1). For the measurement phase, data regarding the DTN times and the modified Rankin Scales were collected on the field and from data warehouse. They regard the period that precedes the HLM adoption (from 1st January 2013 till 28th May 2014) and the post-intervention period (from 29th May 2014 till 31st December 2014). For the latter, only data for patients cared with HLM interventions in the pilot test were considered.

From 2008 to 2013 DTN time had been reduced, but it was still too high. The project goal was to identify which steps were unnecessary before the treatment and to streamline the needed activities to reduce DTN time.

Once evaluated the current state, identified barriers and inefficiencies in the process and developed the metrics to track the improvements, the team analyzed the causes by using 5 Whys model (Fig. 2) in the analysis phase, where also correlation diagrams were created, to test the relation between DTN time and organizational or patient demographic factors (patient age and sex). Thanks to this analysis a relation between DTN time and the different days of the week emerged (the DTN time depends on the week day). On the other side, the correlation analysis performed between the DTN time and the patient age and sex did not demonstrate there is a relation between the DTN time and the investigated demographic factors.

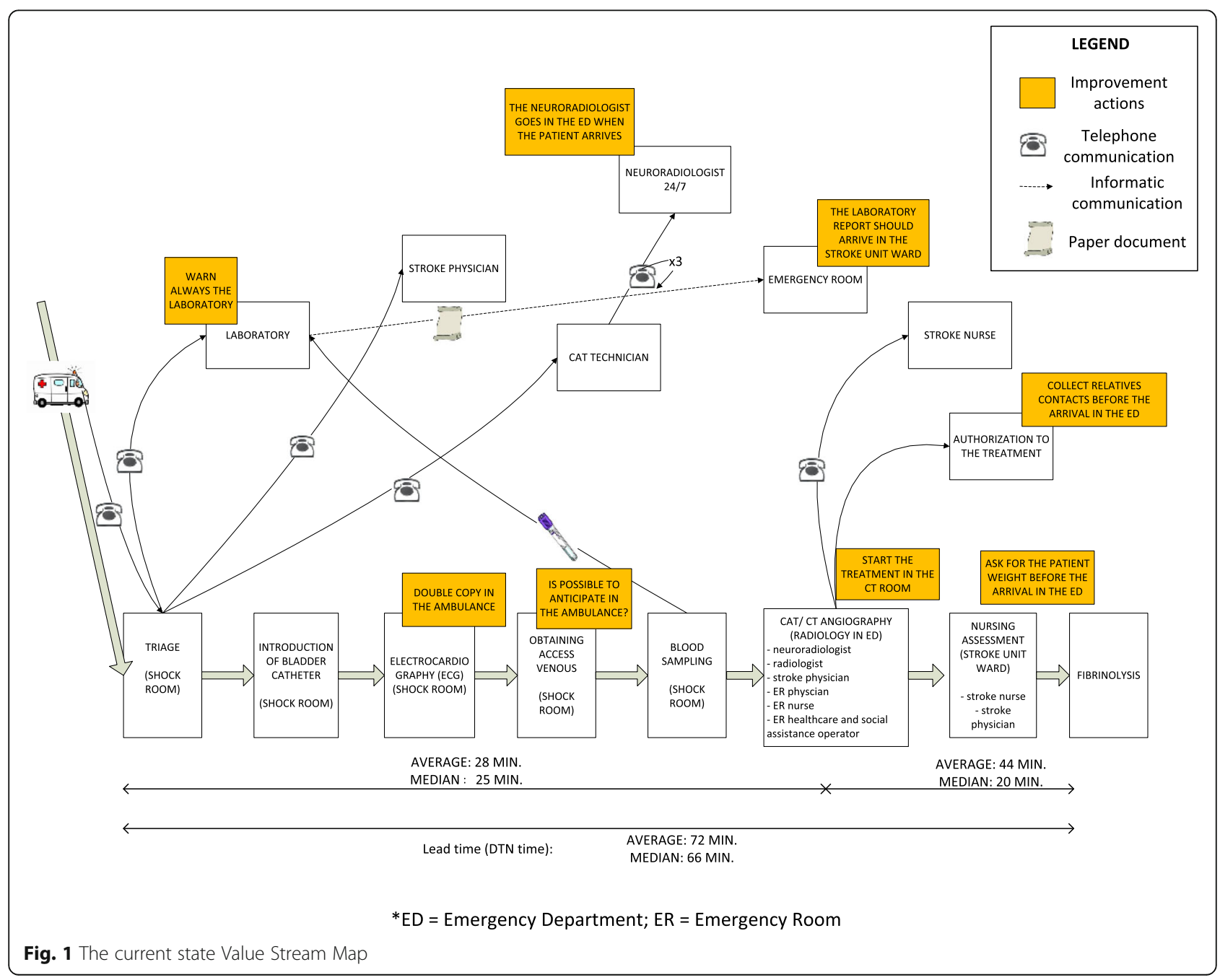




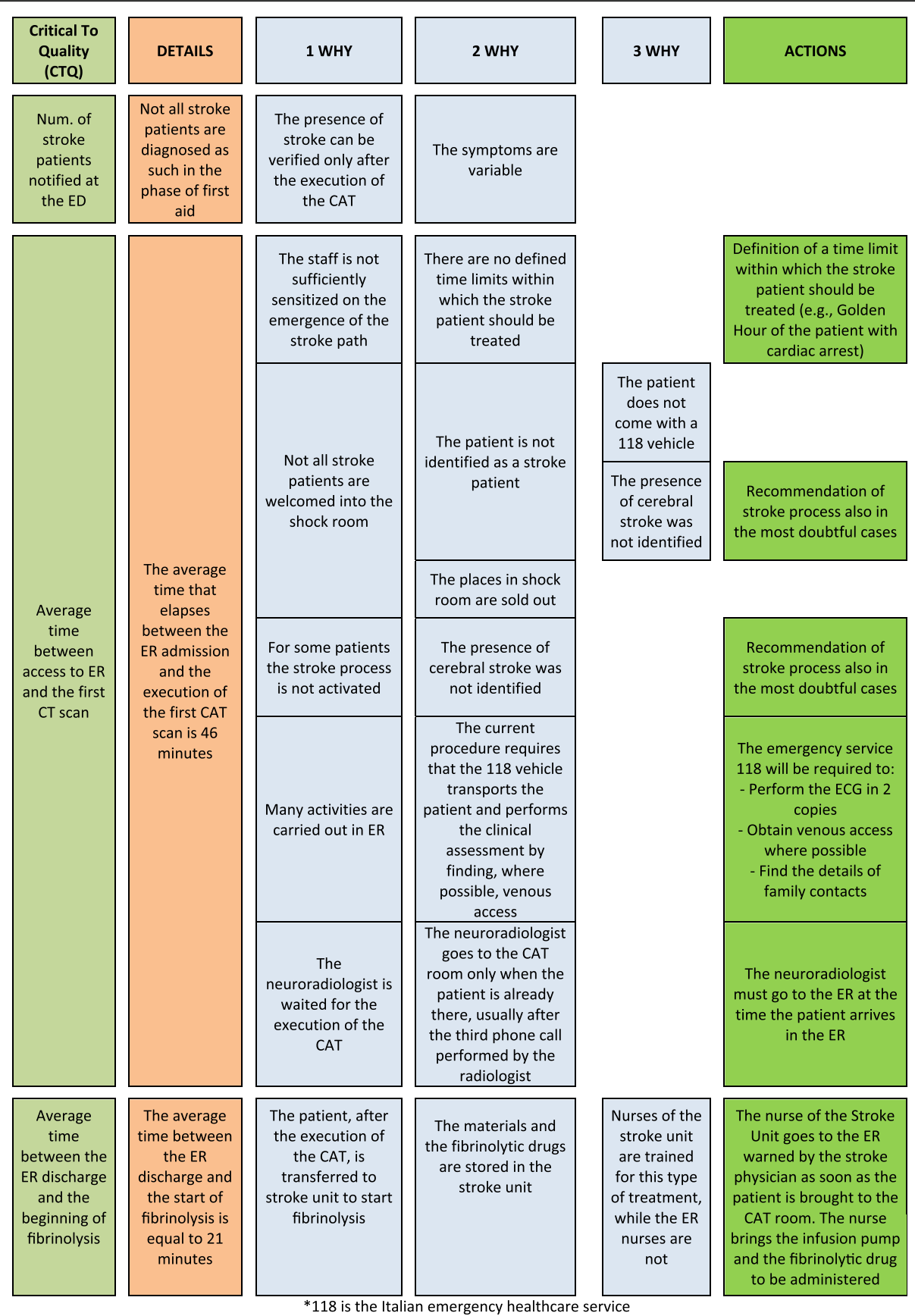

Fig. 2 The 5Whys model

In the analysed case, 3 Whys were enough to achieve the root causes [29]. The results of this technique show that the DTN time depends mainly from organizational factors, improvable with HLM. The team thought about the strategies to eliminate wastes and they developed the ideal state (Fig. 3).

The countermeasures to implement were planned and approved by the Health Director; they were determined following the ECRS (Eliminate, Combine, Reduce,
Simplify) approach [30] and they were defined for each actor involved in the project. First of all, the team decided to eliminate the inefficiencies that didn't request huge efforts (such as obtaining informed consent from the patients, delay reduction in neuroimaging). All the interventions are reported in Table 1 and they were implemented in order to overcome the failure to triage stroke as emergency, reduce the delay in neuroimaging and in medical assessment, eliminate difficulties in 


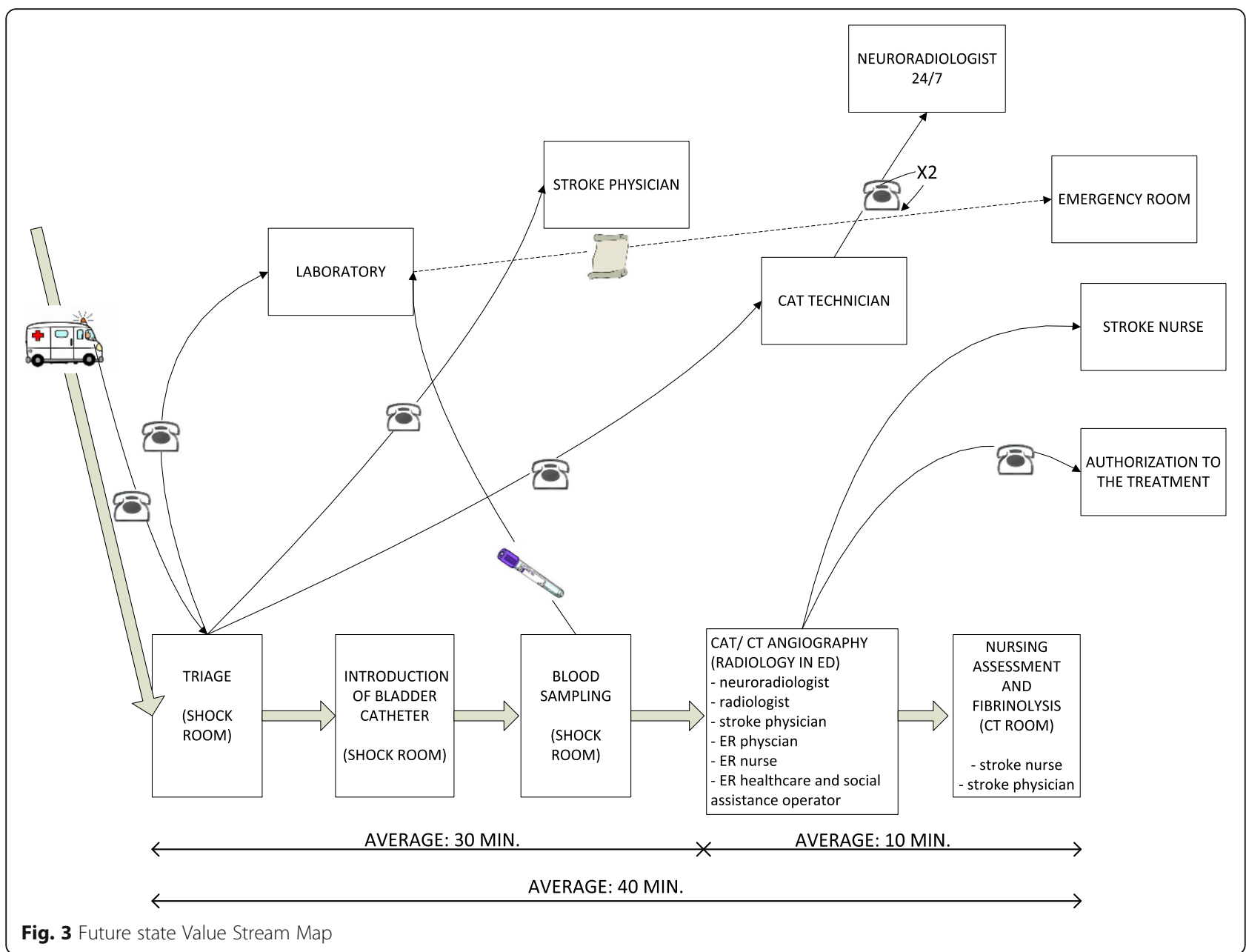

obtaining informed consent, decrease the delay in starting the treatment caused by the distance from the Emergency Department (ED) and the Stroke Unit. For example, the stroke unit nurses were required to go to the ED to start the treatment. To this extent, the unit director signed an authorization to allow the nurses and the physician to leave the ward for the necessary time to start the treatment in ED. This intervention was adopted just from 8 a.m. to 8 p.m. during the pilot period of 3 months and then it was extended to all the hours (day and night) of all the days ( $24 \mathrm{~h} / 7$ days).

\section{Operational and clinical outcomes}

DTN times were and are recorded mandatory for each patient every 3 months. During the project implementation the team started to report and monitor with the same frequency also the modified Rankin Scale (mRS) of each patient discharged from 3 months. MRS is a commonly used scale for measuring the degree of disability or dependence in the daily activities after a stroke $(0$ means "not symptoms at all", 6 means "dead"). The DTN time was reduced to $46 \mathrm{~min}$ at the end of 2014, for the patients cared with HLM interventions in the pilot test. In Table 2 , time reduction of the main process phases is highlighted.

Adopting the Mann-Whitney test, the DTN times regarding the latter patients have been compared with the pre-intervention DTN times. The implemented hypothesis test confirms the improvement of DTN times is highly statistically significance (asymptotic significance (2-tailed) $\mathrm{p}$-value $<0.001)$. With the implemented project, clinical outcome was also improved; even if the statistically significance has not been demonstrated, the mRS decreased from the pre to the post intervention period. The average of mRS moved from 1.48 (the value obtained from the pre-intervention data) to 1.38 (for the data regarding the patients that followed the improved stroke process in 2014).

Besides these operational results, the project has permitted to define the tasks of the employees clearly, and to refine the performance measurement system. In particular, now it is possible to measure not only the total DTN time, but also all the times regarding the different hospital units involved in the stroke care process, 
Table 1 The suggested interventions

\begin{tabular}{|c|c|c|c|}
\hline Unit & Action & Responsible person & $\begin{array}{l}\text { Starting } \\
\text { date }\end{array}$ \\
\hline \multirow[t]{3}{*}{118 Service } & ECG execution in 2 copies to be left in ER & Physician in charge of the emergency service & 10 June \\
\hline & Venous access (where possible) & Physician in charge of the emergency service & 10 June \\
\hline & $\begin{array}{l}\text { Family contacts for fibrinolysis authorization + registration } \\
\text { of full name and date of birth of patient }\end{array}$ & Physician in charge of the emergency service & 10 June \\
\hline \multirow{6}{*}{$\begin{array}{l}\text { Emergency } \\
\text { room }\end{array}$} & Patient admission in Shock Room & ER triage & 10 June \\
\hline & Ensuring two venous access of needle cannula (size 18G) & ER nurse & 10 June \\
\hline & Insertion of bladder catheter & ER nurse & 10 June \\
\hline & Confirmation of the patient arrival by the radiologist & ER triage & 10 June \\
\hline & $\begin{array}{l}\text { Do not perform blood gas test unless the clinical condition } \\
\text { of the patient make this necessary }\end{array}$ & ER nurse & 10 June \\
\hline & Avoiding the placement of the nasogastric tube & ER nurse & 10 June \\
\hline Neuroradiology & $\begin{array}{l}\text { The neuroradiologist goes to CAR room when the } \\
\text { stroke patient arrives in ER (II call) }\end{array}$ & Neuroradiology director & 10 June \\
\hline \multirow[t]{3}{*}{ Stroke unit } & Formalization of the nurse role in the stroke process & $\begin{array}{l}\text { Stroke Unit director + nurse Coordinator of the Stroke } \\
\text { Unit }\end{array}$ & 10 June \\
\hline & Starting of a new procedure for the stroke nurse & $\begin{array}{l}\text { Stroke Unit director + nurse Coordinator of the Stroke } \\
\text { Unit }\end{array}$ & 10 June \\
\hline & Writing of a new procedure & Stroke Unit director & 10 June \\
\hline
\end{tabular}

facilitating the identification of the causes of eventual delays. The organizational system does not undergo significant changes, and the interventions regarded only procedure revisions, but employee satisfaction with the implemented project was reported and it came mainly from the good project outcomes and from the greater consciousness of the executed job, gained thanks to the studied project.

\section{Discussion}

The analysed project has been diffused in Tuscany Region as a best practice and now the University Hospital of Siena is the hospital with the lowest mortality risks within 30 days from the stroke patient discharge in Tuscany Region. The results obtained in terms of patient health contribute to the project sustainability. Moreover, DTN time is continuously under control, and the team would like to expand this experience to the endovascular procedures. According to the conducted interviews, the main project enablers regarded the motivation and determination of the project team, the stroke unit director and the diffusing lean approach. Another important facilitator concerned the type of the analysed problem: in

Table 2 Times of the main phases of the stroke process

\begin{tabular}{llll}
\hline Period & $\begin{array}{l}\text { Total lead } \\
\text { time }(\mathrm{min})\end{array}$ & $\begin{array}{l}\text { Time from door } \\
\text { to } \mathrm{CT}(\mathrm{min})\end{array}$ & $\begin{array}{l}\text { Time from CT to } \\
\text { needle }(\mathrm{min})\end{array}$ \\
\hline Post -HLM intervention & 46,6 & 23,8 & 22,8 \\
Pre - HLM intervention & 71,9 & 28,4 & 43,5 \\
\hline
\end{tabular}

this case if there is a process improvement, the quality of the patient future life will enhance.

However, the stroke nurses were not completely involved from the beginning of the project (only after the presentation of the improvement plan) and initially they created resistance. The nursing coordinator was a member of the team, but there were some issues regarding the internal communication inside the stroke unit. In particular, there wasn't an extensive and continuous information exchange between the nursing coordinator and the other staff not involved in the project.

The clinical results obtained from the study demonstrate how much timeliness and clinical effectiveness are linked together in this peculiar L\&S project. Safety and effectiveness improvements in this case are due to efficiency results, as the saving of $25 \mathrm{~min}$ in the process care means saving millions of neurons. For example, according to the Saver's research, in the case of vessel ischemic stroke saving a minute leads to avoid the loss of "1.9 million neurons, 13.8, billion synapses, and $12 \mathrm{~km}$ (7 miles) of axonal fibers" [8]. Therefore, saving $25 \mathrm{~min}$ means a relevant result for the care of stroke patient. The link between timeliness and clinical effectiveness is justified by the literature for the stroke care and it is confirmed by the decrease of the mRS obtained after the project implementation.

This paper not only provides a contribution to demonstrate the link between these two kinds of performance, but it permits to analyse a particular case of L\&S projects, refining the developing theory about them. Investigating the project objectives and outcomes, safety 
improvements are not enounced as project aim in this case. However, thanks to this peculiar L \& S project it has been demonstrated that for some specific processes (e.g., for stroke process) pursing efficiency enhancement implies pursing also safety and effectiveness increases. Besides the features that are common to other L\&S projects (e.g., top management support and employee involvement), this project has also confirmed that safety and effectiveness results can be achieved only adopting HLM, and particularly, only applying organizational solutions (e.g., the changed procedures). Of course, the latter not always are enough to assure a care delivery of high quality, even if in this specific case they lead to lean the stroke processes, obtaining relevant results.

This paper provides a contribution also from a managerial point of view. In particular, observing the operational and clinical outcomes obtained in the analysed case, hospital managers can consider the adoption of HLM in their settings. If the process that needs interventions has never been improved, a VSM, tools to analyse the causes of the wastes and to monitor the results, following the DMAIC approach, can be considered to achieve operational and clinical results. In some cases, similar to the one analysed, expensive solutions are not required, in that organizational changes revising the traditional care process could be a valuable starting improvement.

Nevertheless, some limitations and possible future research have been identified also for this research. First of all, considering the over-mentioned study of Ford et al. [13], also in this case the statistically significance has not been demonstrated for mRS, even if a positive improvement has been reported. The obtained results should be verified with more data of mRS, collected for the 2015 and so far not available. Furthermore, in this project less attention has been paid to the sociotechnical aspects of the project [31]. They concern, for instance, the staff well-being, team working and communication, or other "soft" aspects, which should be considered together with the operational interventions in future research.

Another limitation of this study is linked to the generalizability of the reported results, as a holistic case study has been conducted. For this reason, similar projects should be implemented and analysed in other units, hospitals, regions, countries testifying the results obtained in this study. It is expected the approach adopted in this research could be helpful also for other processes of care where the achievement of timeliness care determines positive clinical outcomes, such as heart diseases, the process of the femoral fracture, but also other care processes as, for example, reattaching of body parts after accidental amputations.

Moreover, as reported in the literature, reducing only pre-hospital time or only DNT can lead to an increase of one of them, leading to a worse OTT. For this reason, the entire process should be improved considering together the pre-hospital times (the onset to alarm time and the alarm to door time), and the DNT in further researches [7].

Nevertheless, the results obtained in the analysed L\&S project could lead not only to an improvement of the patient well-being, but also it could affect the units of the territory dedicated to the rehabilitation of the stroke patients. In particular, thanks to the improved clinical outcomes they could face easier rehabilitations, reducing the length of stay of the inpatient rehabilitation that imply huge costs, as underlined by [32].

\section{Conclusion}

The paper highlights how following a HLM approach, even adopting only organizational solutions, significant improvements in stroke care process can be achieved, in terms of both timeliness and effectiveness, and without any further economic expenditures. These multiple benefits can be obtained detecting and reducing wastes, following the HLM methodology, every time the object to improve is a process in which shorter time means more effective and safer care. These results give a contribution to the knowledge of how L\&S projects can improve the healthcare quality, to the benefit of the whole society.

\begin{abstract}
Abbreviations
AOUS: Azienda Ospedaliera Universitaria Senese; DMAIC: Define, Measure, Analyse, Improve, Control; DNT: Door to Needle Time; DTN: Door To Needle; ECRS: Eliminate, Combine, Reduce, Simplify; ED: Emergency Department; ER: Emergency Room; HLM: Health Lean Management; KPIs: Key Performance Indicators; L \& S: Lean \& Safety; mRS: modified Rankin Scales; OTT: Onset to Treatment Time; SITS: Safe Implementation of Treatments in Stroke International Network
\end{abstract}

\section{Acknowledgements}

The authors would like to acknowledge the CEO, CMO and CFO of the University hospital of Siena and the head of Siena Stroke Unit.

\section{Funding}

Grant CPDR147702.

Availability of data and materials

Data are available from the corresponding author at request.

Authors' contribution

All authors read and approved the final manuscript.

Competing interests

The authors declare that they have no competing interests.

Consent for publication

Not applicable.

Ethics approval and consent to participate

Ethical approval is not necessary for this study.

\section{Author details}

${ }^{1}$ Department of Management and Engineering, University of Padova, Stradella San Nicola, 3, 36100 Vicenza, Italy. ${ }^{2}$ Lean Office, University Hospital of Siena, Viale Bracci, 53100 Siena, Italy. 
Received: 15 July 2016 Accepted: 20 September 2016

Published online: 29 September 2016

\section{References}

1. American Heart Association. Heart disease and stroke statistics - at a glance. 2015. https://www.heart.org. Accessed 26 May 2016.

2. Stroke association. State of the Nation. Stoke statistics. 2016. https://www. stroke.org.uk/sites/default/files/stroke_statistics_2015.pdf. Accessed 26 May 2016.

3. Krishnamurthi RV, Feigin VL, Forouzanfar MH, Mensah GA, Connor M, Bennett DA, et al. Global and regional burden of first-ever ischaemic and haemorrhagic stroke during 1990-2010: findings from the Global Burden of Disease Study 2010. Lancet Glob Health. 2013;1(5):e259-81.

4. Thrift AG, Cadilhac DA, Thayabaranathan T, Howard G, Howard VJ, Rothwell PM, et al. Global stroke statistics. Int J Stroke. 2014:9(1):6-18.

5. Sacco RL, Kasner SE, Broderick JP, Caplan LR, Culebras A, Elkind MS, et al. An updated definition of stroke for the 21st century a statement for healthcare professionals from the American Heart Association/America. Stroke. 2013; 44(7):2064-89.

6. Gomez CR. Time is brain. J Stroke Cerebrovasc Dis. 1993;3(1):1-2.

7. Li LM, Johnson S. Lean thinking turns 'time is brain' into reality. Arq Neuropsiquiatr. 2015;73(6):526-30.

8. Saver JL. Time is brain-quantified. Stroke. 2006;37(1):263-6.

9. Jauch EC, Saver JL, Adams HP, Bruno A, Connors JJ, Demaerschalk BM, et al. Guidelines for the early management of patients with acute ischemic stroke a guideline for healthcare professionals from the American Heart Association/American Stroke Association. Stroke. 2013;44(3):870-947.

10. Smith EE, von Kummer R. Door-to-needle times in acute ischemic stroke How low can we go? Neurology. 2012;79(4):296-7.

11. Ebinger $M$, Winter $B$, Wendt $M$, Weber JE, Waldschmidt C, Rozanski M, et al. Effect of the use of ambulance-based thrombolysis on time to thrombolysis in acute ischemic stroke: a randomized clinical trial. Jama. 2014;311(6):1622-31.

12. Meretoja A, Strbian D, Mustanoja S, Tatlisumak T, Lindsberg PJ, Kaste M. Reducing in-hospital delay to 20 minutes in stroke thrombolysis. Neurology. 2012;79(4):306-13.

13. Ford AL, Williams JA, Spencer M, McCammon C, Khoury N, Sampson TR, et al. Reducing door-to-needle times using Toyota's lean manufacturing principles and value stream analysis. Stroke. 2012;43(12):3395-8.

14. Kim SK, Lee SY, Bae HJ, Lee YS, Kim SY, Kang MJ, et al. Pre-hospital notification reduced the door-to-needle time for IV t-PA in acute ischaemic stroke. Eur J Neurol. 2009;16(12):1331-5.

15. Köhrmann M, Schellinger PD, Breuer L, Dohrn M, Kuramatsu JB, Blinzler C, et al. Avoiding in hospital delays and eliminating the three-hour effect in thrombolysis for stroke. Int J Stroke. 2011;6(6):493-7.

16. Aronsson H, Abrahamsson M, Spens K. Developing lean and agile health care supply chains. Supply Chain Manag Int J. 2011;16(3):176-83.

17. Womack JP, Jones DT. Lean Thinking - Banish waste and create wealth in your corporation. New York: Free Press; 2003.

18. Radnor Z. Implementing lean in health care: making the link between the approach, readiness and sustainability. Int J Ind Eng Manag. 2011;2(1):1-12.

19. Barnes-Jewish Hospital. Barnes-Jewish Hospital applies lean methodology to acute stroke care, maximizing resources and slashing door-to-needle times. ED Manag. 2013;25:13-7.

20. Whiteman RM, Leblanc K, Dineen L, Venditti D, Maderer C, MacRae L, et al. Utilization of lean methodology to achieve efficiencies in acute ischemic stroke quality based procedure implementation. Int J Stroke. 2015;10(4):76.

21. Pagliuso SA, Navasero N, Rose S, St Amant B, Zubic G. A lean approach to maximizing stroke rehab intensity. Int J Stroke. 2015;10:95.

22. Crema M, Verbano C. How to combine lean and safety management in health care processes: a case from Spain. Saf Sci. 2015;79:63-71.

23. Crema M, Verbano C, Chiozza ML. First evidences from "lean \& safety" projects. Int J Qual Serv Sci. 2015;7(2/3):245-59.

24. Carbone C, Lega F, Marsilio M, Mazzocato P. Lean on lean? Indagine sul perché e come il lean managementsi sta diffondendo nelle aziende sanitarie italiane. In CERGAS. Osservatorio sulle aziende e sul sistema sanitario italiano. Rapporto OASI 2013: Egea; 2013. 393-427.

25. Yin R. Case Study Research: Design and Methods. 4th ed. Thousand Oaks: Sage Publications; 2009.

26. Voss C, Tsikriktsis N, Frohlich M. Case research in operations management Int Oper Prod Manag. 2002;22(2):195-219.
27. Hyer NL, Wemmerlöv U, Morris JA. Performance analysis of a focused hospital unit: the case of an integrated trauma center. J Oper Manag. 2009; 27(3):203-19.

28. Kwak YH, Anbari FT. Benefits, obstacles, and future of six sigma approach. Technovation. 2006;26(5):708-15.

29. Pylipow PE, Royall WE. Root cause analysis in a world-class manufacturing operation. Quality. 2001;40(10):66-70.

30. Pawar GJ, Sirdeshpande NS, Atram AB, Patil PR. Reduction in setup change time of a machine in a bearing manufacturing plant using SMED and ECRS. Int J Adv Ind Eng. 2014;3:321-3.

31. Joosten T, Bongers I, Janssen R. Application of lean thinking to health care: issues and observations. Int J Qual Health Care. 2009;21(5):341-7.

32. Meyer M, Britt E, McHale HA, Teasell R. Length of stay benchmarks for inpatient rehabilitation after stroke. Disabil Rehabil. 2012;34(13):1077-81.

\section{Submit your next manuscript to BioMed Central and we will help you at every step:}

- We accept pre-submission inquiries

- Our selector tool helps you to find the most relevant journal

- We provide round the clock customer support

- Convenient online submission

- Thorough peer review

- Inclusion in PubMed and all major indexing services

- Maximum visibility for your research

Submit your manuscript at www.biomedcentral.com/submit
) Biomed Central 